\title{
The Demographic Gift in Australia
}

\author{
Natalie Jackson and Bruce Felmingham
}

$\mathrm{T}$

The demographic gift describes the effects generated by the coincidental occurrence of declining birth rates and increasing life expectancy, a legacy of the phenomenon known as 'the demographic transition'. The gift refers to the relatively brief (2-3 decades) period during which the proportion of the population aged 15-64 years is at its maximum; correspondingly the proportions dependent at the younger and older ages are at their minimum. At this point in the demographic transition, the working age population also grows considerably faster than the total population.

The relevance of these demographic concepts to economic analysis is the income effects of the gift itself, and it is this attribute that has motivated the study of the demographic gift in many developing and newly developed countries (Birdsall, Kelley and Sinding, 2001; Bloom and Canning, 2003; Mason, 2003). Interestingly, the phenomenon has received much less scholarly interest in the developed countries, despite it having delivered to them empirically verifiable economic benefits. Ironically, it may only be with the emergence of the gift in the developing countries and its simultaneous loss in the developed countries that the phenomenon will be afforded the recognition it deserves.

The objective of this study is to assess the magnitude of the demographic gift in Australia, and the impact of its impending loss. It also considers the effect of the baby boom (1946-65) and baby 'bust' (1966 to late-1970s) in prolonging the period of gift. The baby boomers are now moving through the highest income earning groups, namely, the age groups 35-44 years and 45-54 years. They are followed by a band of significantly extended 'baby boom echo' cohorts born in the period 1969-72 who are only just approaching the first of these highest incomeearning age groups. Inappropriately defined as the period of the 'baby bust', the late 1960s and 1970s saw dramatically falling birth rates per woman, but in 1971 also saw the birth of Australia's largest-ever birth cohort - the multiplicative effect of increased numbers of men and women (the 'leading edge' baby boomers) reaching reproductive age.

These inter-related phenomena are evident in Figure 1, which illustrates the differing trends of the total fertility rate (average births per woman) and cohort size (actual birth numbers). It is our central thesis that the passage of the echo or baby bust cohorts into and through the highest income earning age groups over the next several decades will significantly ameliorate Australia's loss of 'the gift' as it has been conventionally defined.

Natalie Jackson is Senior Lecturer in Social Demography, School of Sociology and Social Work, and Bruce Felmingham is Reader in Economics, School of Economics, both at the University of Tasmania 
Figure 1: Total Fertility Rates, Cohort Size, the Baby Boom and 'Baby Bust', Australia, 20th Century

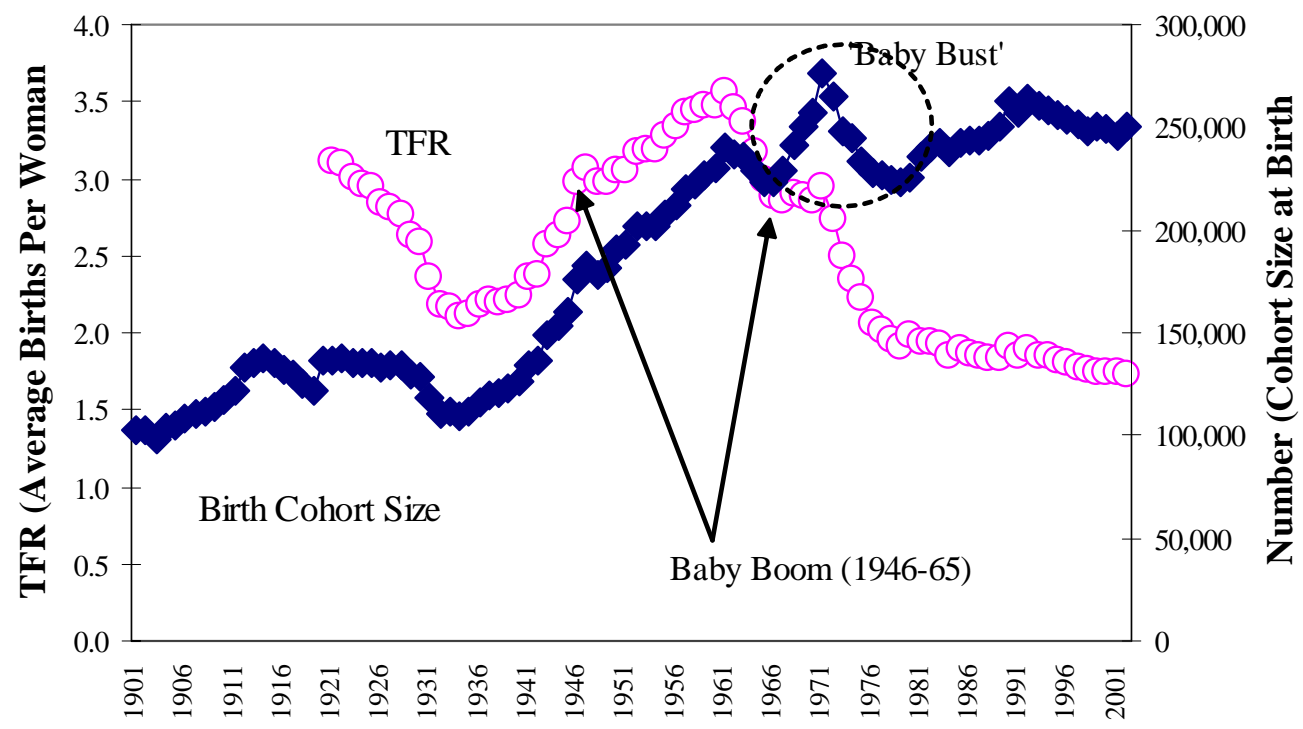

Source: ABS Births, various years

Another contribution of this study is that the size of the demographic gift is assessed at both national and regional levels. Our extension to cover the individual States and Territories of the Australian Commonwealth follows Jackson and Felmingham (2002), who find that the timing and speed of the structural ageing process differs markedly across the Australian States and Territories. Regional disparities carry substantial policy significance, particularly for institutions and fiscal transfer arrangements such as those allocated by the Commonwealth Grants Commission and to the States Grants Commissions.

A number of caveats must be entered at the outset. First, the size of Australia's demographic gift has been and will continue to be influenced by international migration, which in Australia typically augments each birth cohort as it passes through its twenties and thirties. The 1971 cohort, for example (currently aged 32 years), numbered 276,362 at its birth, and 315,666 in 2002. However, over the longer term, migration tends to have a similar impact on each cohort, and so it has minimal effect on the overall age structure (Kippen and McDonald, 2000). In 2003 the 1971 cohort remains Australia's largest, and it is projected to remain so for a further three decades.

Second, in considering the future loss of the gift, the study uses the age-sex specific income distribution for 2001 and projects it forward according to the Australian Bureau of Statistics high variant (Series I) population projections (ABS, 2000). This methodology illustrates what would occur if there were no change in the income distribution over the base year, and the high variant 
assumptions regarding births, deaths and migration prevail. Accordingly, there is no intention to imply that these economic projections are 'forecasts' of future aggregate earnings. Indeed it is our thesis that there will be significant changes to the age-sex income distribution as the demographic trends we outline here unfold, not least those affecting the ratio of labour market entrants to exits, which in all probability will see substantial improvements in labour market demand for the young.

Third, to advance this study, the age distribution is treated as an exogenous variable, although the related significance of explaining the various causes and dynamics of the gift is an acknowledged issue. In this study, the link between the resulting size of the gift and its economic manifestation is confined to an examination of the correlation between the size of the gift and per capita GDP, and to its impact on aggregate earnings.

\section{Australia’s Demographic Gift}

In its original formulation, the demographic gift is derived from demographic events that increase the proportion of the population aged 15 to 64 . By convention, these are primary working age (and therefore primary income earning) people. The limiting ages of this conventional measure of the working age population are contestable. The lower limit of 15 years does not account for increasing participation in senior secondary or tertiary education, while the upper limit ignores the recent tendency towards early retirement. However, to counter these arguments, many school and tertiary students undertake part time and casual work, reinforcing the case for an arbitrary lower age limit of 15 years. Pressures for people to work longer are also now reversing the trends toward early retirement, making 65 years of age an appropriate benchmark for a future-oriented study. Finally, international labour market data, such as that generated by the International Labour Office, the OECD, United Nations, and World Bank are typically based on a 15-64 year old (or 15+ year) 'working age' population. The case for changing this conventional view of the working age population is not strong enough to counter the benefits of maintaining a basis for comparison with other studies.

The historical record and projections to 2051 of the proportion of the Australian population aged 15-64 years are shown in Figure 2, along with an illustration of 'the gift' in terms of GDP per capita over the years 1959-2002.

The data over the period 1901 to 2002 show that the proportion of Australia's population in the primary working age group peaked in 1943 when 68.2 per cent of the population was of working age. The dip evident over the 1960s reflects the effects of the ensuing baby boom in reducing the proportion in the working age population: the proportion of the population aged 0-14 years peaked at 30 percent in 1961. The projections to 2051 indicate that the working age proportion will reach a second and final peak about 2008, at around 67.8 percent of the population. The decline in the projected working age proportion thereafter will by 2051 reduce the proportion below 60 per cent, some 2.2 per cent below its trough 
in 1961. These 'otherwise indicative' trends should be considered fairly robust over the next few decades at least, as most of the people they represent are already in the population age structure.

Figure 2: The Demographic Gift (Percentage Aged 15-64 Years) 19012051, and GDP per capita (1960-2002, Indexed to 1960)

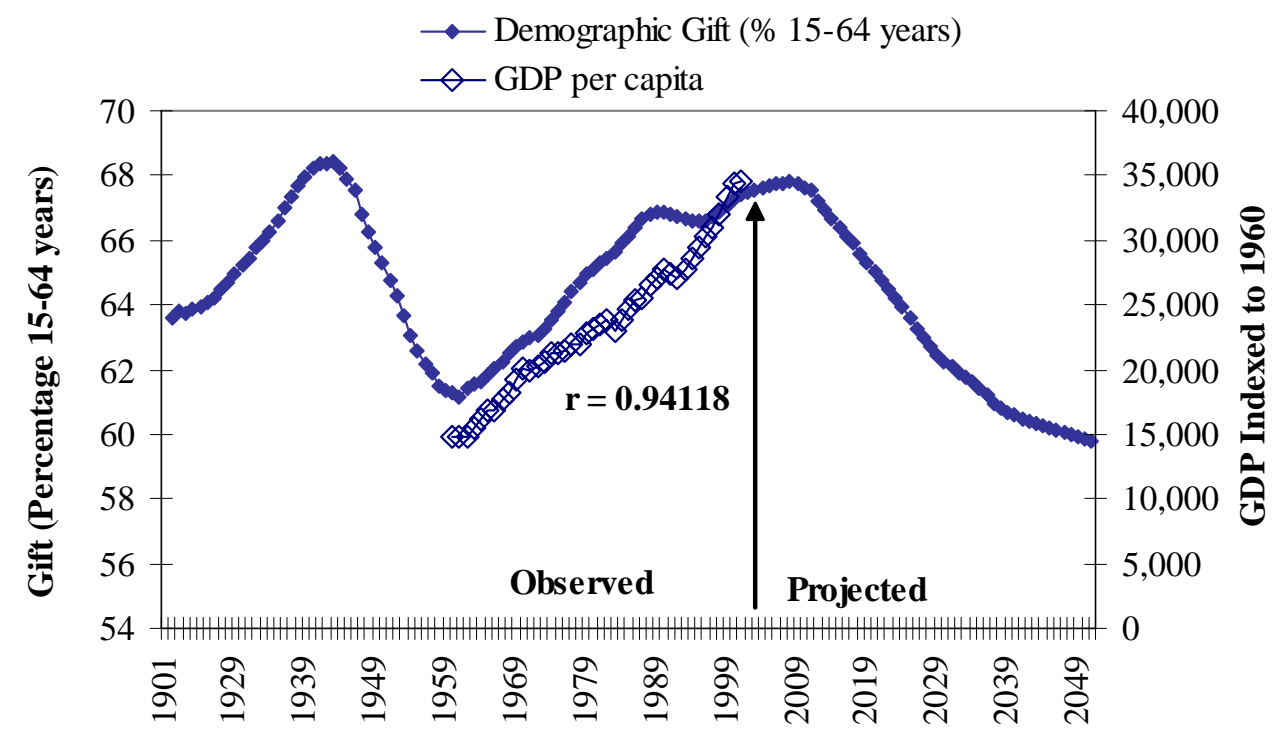

Note: Projections of the working age proportion over the period 2003 to 2051 are based on the high variant assumptions underpinning the Australian Bureau of Statistics (ABS, 2000) Series 1 population projections: a constant annual net migration gain of 110,000, a constant Total Fertility Rate of 1.75 from 2009, and life expectancy increasing by approximately 1 year for every 10 years projected.

Source: 1901-2001 ABS Estimated Resident Population; 2002-2051 ABS Population Projections 1999-2051 Catalogue 3222.0, Series I; ABS Leading Indicator Series

Some indication of the relationship between these working age population trends and key economic variables such as income (earnings) is provided in the simple correlation analysis of the proportion of the population aged 15-64 years and GDP per capita, shown on the graph as $r=0.94$. The correlation is striking, and while GDP per capita is influenced by many other economic factors it is clear that a prima facie case exists for a further analysis of the population/economic activity nexus using Australian data.

The results of other Australian studies focussed on the nexus between demographic and macroeconomic characteristics are mixed. This view certainly applies to the recent debate about population ageing and aggregate saving in Australia. The genesis of this debate is to be found in the work of Fitzgerald 
(1993), later supported by Argy (2001) and Wood (2001) who posit that Australians are not saving enough presently to support an older Australian population in future and that some policy intervention is required. However, Guest and McDonald (1998), using their own model of optimal saving, conclude that Australian households were thrifty over the period 1960-1961 to 1973-74, over-saving in relation to optimal savings by 5.3 percent. Conversely the years from 1974-75 to 1994-95 were characterised by undersaving, but this was only 1.7 per cent below the optimal level. The same authors - Guest and McDonald (2001) - explore the specific effects of population ageing on Australia's living standards. They find that population ageing puts a slight downward pressure on living standards until 2050, but they also conclude that age-adjusted living standards will continue to increase, although at a reduced annual rate of 1.2 percent. In summary, the Guest and McDonald findings are that the effects of structural population ageing on living standards are small and, contrary to their earlier recommendations, they do not recommend policy intervention. The following analysis, which assesses the personal income effects of the gift and its impending loss, may assist in explaining Guest and McDonald's results. It also contributes to the argument regarding the need for policy intervention.

Figure 3 shows the impact of changes in age structure on aggregate earnings (our proxy for personal income), first across the 1976-2001 period, and then projected from 2001 to 2051 . However, before discussing the results, we note the method by which we obtained them. For the first period (1976-2001), aggregate median annual incomes by age and sex were derived from Census data (ABS 'unpublished' customised database) for each of the six observations 1976-2001 (data available on request). Using the technique of direct standardisation (see Pollard, Yusuf and Pollard, 1974:64-67), the age-sex structure was then held constant at its 1976 percentage distribution, and applied to the underlying age-sexspecific income data for each observation to show what the aggregate annual earnings for each observation would have been if the age-sex structure had remained constant at its 1976 distribution. The difference between the two resulting aggregate earnings values is the effect of actual changes in the age structure across the period.

For the second period (2001-2051), the median weekly incomes for 2001 for each age-sex group were held constant at their 2001 dollar values and projected to 2051 by applying to them the numbers projected to be in each age-sex group at each observation. The results were then summed and multiplied by 52 (weeks) to give weighted aggregate annual earnings for each observation. The 2001 age-sex income data were then separately projected to 2051 by holding the age-sex structure constant at 2001 (percentage distribution) values, and applying it to the projected total population size for each observation. This latter process (a combination of direct and indirect standardisation) derived the number that would be in each age-sex group at each year if there were no changes to the age structure, and the aggregate weekly earnings of each age-sex group under these conditions. The difference between the two resulting aggregate earnings values is the dollar effect of projected changes in the age structure across the period. 
The resulting data presented in Figure 3 show a small but positive contribution from age structure to aggregate earnings across the 1976-2001 period, peaking at 3.2 per cent in 1996 and then reducing to 2.5 per cent in 2001. In dollar terms these contributions appear more significant - in 2001, for example, the change in age structure over 1976 contributed around 8.4 billion dollars to aggregate income. The projections to 2051 then show a slowly increasing negative contribution, reaching 1.9 per cent by 2011 and 8.6 per cent by 2051 . That is, by 2051, if the age-sex income distribution extant in 2001 and the assumptions underlying the high variant population projections were to prevail, population ageing would reduce aggregate earnings by around 8.6 per cent over what they would be if the age structure remained constant. At 2001 dollar values this amounts to a reduction of some 37.4 billion dollars by 2051. However, it should be noted that this reduction will occur alongside an overall growth in aggregate earnings - the overall effect of an increase in the size (as opposed to proportion) of the working age population, albeit at a decelerating rate. Ceteris paribus, aggregate earnings will increase from their present 312 billion dollars, to around 439 billion dollars by 2051. Again we reiterate the point that this analysis includes consideration of projected demographic change only.

\section{Figure 3: Percentage Contribution of Age Structure to Aggregate Earnings, 1976-2001 and Projected 2001-2051, Australia}

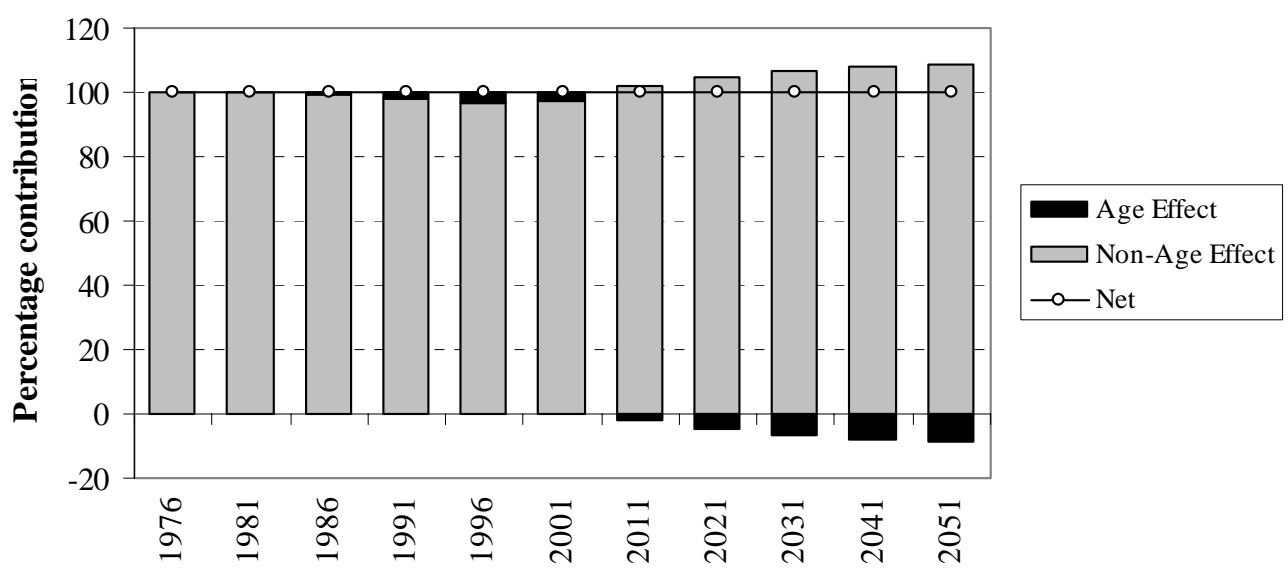

Source: Authors: 1976-2001; ABS customised database; 2001-2051; ABS (2000) Population Projections, Catalogue 3222.0 Series I; and ABS Basic Community Profiles, Catalogue 2001.0.

Changes in the Australian age structure will thus act to reduce aggregate earnings over what they would have been if the age structure were to remain constant. The trend will accelerate from 2011, the year in which the first of the 
baby boomers will reach age 65 and begin their en masse passage out of the primary working age group. Accordingly, we can conclude that on this conventional understanding and measurement of the demographic gift, its peak dividends have been realised.

We note here a further minor caveat. For various reasons the analyses for the two periods were carried out separately, using two different earnings databases, and bought together for the purpose of more clearly explicating the shift from positive to negative contribution. This methodology introduces a slight but not significant disjunction at the 2001 locus. The approach is justified by the practical difficulties of forecasting how factors affecting the real values of weekly income might change.

\section{The Demographic Gift at State and Territory Level}

The same methodology as was applied to Australia overall can be applied to each State and Territory. However, for the present purposes, an analysis of the projected period 2001-2051 above will suffice. Using the same ABS (2000) high variant projections, but this time for States and Territories, Table 1 shows the relative contribution to (or more accurately, reduction of) aggregate earnings made by age structure.

The findings reflect the differing quantum and tempo of population ageing across the states and territories, a point that we elaborate further below. Tasmania, currently the fastest ageing region, sees a larger percentage (reduction) effect by 2011 than does any other region. However, the difference between Tasmania on the one hand, and South Australia, Victoria, and the currently younger, but soonto-age-faster ACT, on the other, is minimal, and, on the demographic assumptions underlying these high variant projections, Tasmania 'recovers' demographically, and soon experiences a relatively smaller effect on earnings than these regions. By 2021, the effect for Tasmania is somewhat smaller than for each of South Australia, Victoria, the ACT and New South Wales. Importantly, at each observation across the period, four States/Territories experience greater percentage reductions than does total Australia, and four experience less. This somewhat predictable outcome, which can be conceptualised as 'winners' and 'losers', is the one that we have been concerned to show: it is invisible in typical analyses of population ageing at the national level.

A second equally significant observation is evident in Table 1 . While the total aggregate earnings of Total Australia, the ACT, New South Wales, Queensland, Western Australia, and the Northern Territory continue to grow across the projection period, reflecting projected growth in their working age populations per se, those for South Australia and Tasmania peak and begin to decline from 2011 and 2021 respectively, the same occurring for Victoria from 2031. Again the ceteris paribus caveat must be noted. 
Table 1: Projected Effect of Population Ageing on Aggregate Annual Earnings

\begin{tabular}{|c|c|c|c|c|c|c|}
\hline & 2001 & 2011 & 2021 & 2031 & 2041 & 2051 \\
\hline \multicolumn{7}{|l|}{ TOTAL AUSTRALIA } \\
\hline Percentage Effect (\% reduction) & 0.0 & -1.9 & -4.4 & -6.6 & -7.9 & -8.6 \\
\hline Value reduction (\$ Billions) & 0.0 & -6.7 & -16.6 & -26.8 & -33.5 & -37.7 \\
\hline Aggregate Annual Income* (\$ Billions) & 312.3 & 349.9 & 379.8 & 404.2 & 424.0 & 439.6 \\
\hline \multicolumn{7}{|l|}{ TASMANIA } \\
\hline Percentage Effect (\% reduction) & 0.0 & -2.2 & -4.2 & -5.9 & -7.1 & -7.8 \\
\hline Value reduction (\$ Billions) & 0.0 & -0.1 & -0.3 & -0.4 & -0.4 & -0.5 \\
\hline Aggregate Annual Income* (\$ Billions) & 6.3 & 6.5 & 6.6 & 6.5 & 6.2 & 5.9 \\
\hline \multicolumn{7}{|l|}{ SOUTH AUSTRALIA } \\
\hline Percentage Effect (\% reduction) & 0.0 & -2.0 & -4.7 & -7.0 & -8.3 & -9.0 \\
\hline Value reduction (\$ Billions) & 0.0 & -0.5 & -1.1 & -1.6 & -1.8 & -1.8 \\
\hline Aggregate Annual Income* (\$ Billions) & 22.0 & 22.7 & 22.7 & 22.2 & 21.4 & 20.2 \\
\hline \multicolumn{7}{|l|}{ VICTORIA } \\
\hline Percentage Effect (\% reduction) & 0.0 & -2.1 & -4.8 & -7.4 & -8.9 & -9.6 \\
\hline Value reduction (\$ Billions) & 0.0 & -1.8 & -4.1 & -6.5 & -7.8 & -8.3 \\
\hline Aggregate Annual Income* (\$ Billions) & 77.4 & 83.1 & 86.2 & 87.5 & 87.7 & 87.0 \\
\hline \multicolumn{7}{|l|}{ ACT } \\
\hline Percentage Effect (\% reduction) & 0.0 & -2.0 & -4.9 & -7.8 & -9.7 & -11.1 \\
\hline Value reduction (\$ Billions) & 0.0 & -0.1 & -0.3 & -0.5 & -0.6 & -0.8 \\
\hline Aggregate Annual Income* (\$ Billions) & 6.9 & 7.9 & 8.7 & 9.4 & 10.0 & 10.5 \\
\hline \multicolumn{7}{|l|}{ NEW SOUTH WALES } \\
\hline Percentage Effect (\% reduction) & 0.0 & -1.9 & -4.7 & -7.0 & -8.4 & -9.1 \\
\hline Value reduction (\$ Billions) & 0.0 & -2.3 & -6.0 & -9.6 & -11.9 & -13.3 \\
\hline Aggregate Annual Income* (\$ Billions) & 110.0 & 121.4 & 129.8 & 136.6 & 141.8 & 145.7 \\
\hline \multicolumn{7}{|l|}{ QUEENSLAND } \\
\hline Percentage Effect (\% reduction) & 0.0 & -1.6 & -3.6 & -5.5 & -6.7 & -7.4 \\
\hline Value reduction (\$ Billions) & 0.0 & -1.1 & -2.8 & -5.0 & -6.7 & -8.1 \\
\hline Aggregate Annual Income* (\$ Billions) & 55.5 & 67.6 & 79.3 & 90.0 & 99.8 & 108.6 \\
\hline \multicolumn{7}{|l|}{ WESTERN AUSTRALIA } \\
\hline Percentage Effect (\% reduction) & 0.0 & -1.5 & -4.0 & -6.2 & -7.5 & -8.3 \\
\hline Value reduction (\$ Billions) & 0.0 & -0.6 & -1.7 & -2.8 & -3.8 & -4.4 \\
\hline Aggregate Annual Income* (\$ Billions) & 30.5 & 36.2 & 41.2 & 45.8 & 49.9 & 53.6 \\
\hline \multicolumn{7}{|l|}{ NORTHERN TERRITORY } \\
\hline Percentage Effect (\% reduction) & 0.0 & -0.9 & -1.9 & -3.2 & -4.1 & -4.7 \\
\hline Value reduction (\$ Billions) & 0.0 & 0.0 & -0.1 & -0.2 & -0.3 & -0.4 \\
\hline Aggregate Annual Income* (\$ Billions) & 3.5 & 4.5 & 5.5 & 6.5 & 7.7 & 8.9 \\
\hline
\end{tabular}

Notes: *After reduction of ageing effect

- States and Territory Totals do not sum exactly to Total Australia due to rounding effects of using States, Territories and Total data separately.

Source: Calculated by the authors from ABS Basic Community Profiles 2001.0 Table B13 and ABS Population Projections 1999-2100 Catalogue 3222.0 
However, it is only when these two elements of the analysis are drawn together that we can begin to appreciate the full significance of the regionallydiffering changes in age structure. Were it not for their currently more rapid ageing, the aggregate earnings of Tasmania, South Australia and Victoria would not begin to decline in absolute terms for a full decade beyond those specified years. (These outcomes can be observed by adding rather than subtracting age effect to total aggregate earnings). At the same time, the substantially greater impact for the ACT - a reduction of 11.1 per cent by 2051 compared with 8.6 per cent nationally — is illustrative of the more rapid ageing that region is projected to experience from 2011.

Conceptualised in this manner, the regionality of population ageing in Australia has significant implications for each region's aggregate earnings - in some cases negative, in others, positive. However, here we must pause and ask if this formulation of 'the problem' is in fact the correct one? We turn to a consideration of a closely related index: the median individual, and where he or she is located in terms of their earning capacity.

\section{The Median Individual and the Duration of the Demographic Gift}

Presently in Australia, the age of the median person is 35.9 years. He or she was born in 1968, shortly after the peak of the baby boom, which occurred in 1961. Paradoxically, as indicated earlier, the current median individual was born prior to 1971 when the most populous of Australia's age cohorts was born. This paradox is explained by the momentum effect, which refers to the growth potential of the population age structure even as fertility declines. Increasing numbers of people continue to reach reproductive age in each successive year due in part to the higher fertility rates prevailing when they were born, and in part to increasing life expectancy. Even when fertility falls below the generational replacement rate of 2.1 births per woman, these distended cohorts continue for a time to produce successively larger numbers of children, because the size of the birth cohort is the combined effect of the birth rate and the numbers of women at reproductive age. In the Australian case, the birth rate had fallen to 2.9 births in 1971. However, by 1971, the first of the baby boomers had arrived at reproductive age, an effect that added a further three quarters of a million more women to the reproductive age group. So, although the birth rate per woman was lower, the increased number of reproductive age women delivered to Australia its largest birth cohort in 1971. Ironically, this momentum-derived cohort was born during the so-called baby bust, the period between the mid 1960s and 1970s when birth rates plummeted.

The economic importance of the median individual is that aggregate earnings are at their maximum when the median individual is in this highest income earning age group, and will decline as he/she moves through the age distribution to lower income groups. The median individual has only recently (in the year 2000) entered Australia's historically highest earning income age group (full time earnings), namely, the 35 to 44 year group. He or she will remain in this key age 
group until at least 2041 on the assumptions of the ABS medium variant projections, or 2051 on the high variant assumptions (ABS, 2000). This implies a period of 'concentrated gift' of a minimum 41 years for Australia overall. This association of age and income distribution at age 35-44 provides a different approach to measuring the income effects of the demographic gift generated by the momentum effect, as these effects are being sustained by the baby bust cohorts.

Table 2: Projected Shares of Working Age Population and Aggregate Weekly Earnings, By Age, Australia 2001-2051

\begin{tabular}{|c|c|c|c|c|c|c|}
\hline & 2001 & 2011 & 2021 & 2031 & 2041 & 2051 \\
\hline \multicolumn{7}{|l|}{$\begin{array}{l}\text { Percentage share of working } \\
\text { age population }\end{array}$} \\
\hline $15-19$ & 8.7 & 8.0 & 7.3 & 6.9 & 6.8 & 6.6 \\
\hline $20-24$ & 8.9 & 8.3 & 7.6 & 7.3 & 7.2 & 7.1 \\
\hline $25-34$ & 18.9 & 16.9 & 16.0 & 14.9 & 14.5 & 14.4 \\
\hline $35-44$ & 19.1 & 17.7 & 16.1 & 15.5 & 14.7 & 14.5 \\
\hline $45-54$ & 17.1 & 17.1 & 16.2 & 15.1 & 14.9 & 14.4 \\
\hline $55-64$ & 11.7 & 14.8 & 15.2 & 14.8 & 14.1 & 14.2 \\
\hline $65-74$ & 8.4 & 9.5 & 12.4 & 13.2 & 13.2 & 12.9 \\
\hline $75+$ & 7.1 & 7.7 & 9.2 & 12.3 & 14.7 & 16.0 \\
\hline TOTAL & 100.0 & 100.0 & 100.0 & 100.0 & 100.0 & 100.0 \\
\hline \multicolumn{7}{|l|}{$\begin{array}{l}\text { Percentage share of } \\
\text { aggregate weekly income }\end{array}$} \\
\hline $15-19$ & 1.0 & 1.0 & 0.9 & 0.9 & 0.9 & 0.9 \\
\hline $20-24$ & 8.2 & 7.8 & 7.3 & 7.2 & 7.1 & 7.1 \\
\hline $25-34$ & 24.8 & 22.6 & 21.9 & 20.8 & 20.5 & 20.4 \\
\hline $35-44$ & 25.3 & 23.8 & 22.3 & 21.9 & 21.1 & 20.9 \\
\hline $45-54$ & 22.5 & 22.8 & 22.2 & 21.1 & 21.1 & 20.5 \\
\hline $55-64$ & 9.5 & 12.1 & 12.7 & 12.7 & 12.3 & 12.4 \\
\hline $65-74$ & 4.7 & 5.3 & 7.2 & 7.8 & 7.9 & 7.7 \\
\hline $75+$ & 4.1 & 4.6 & 5.5 & 7.6 & 9.2 & 10.0 \\
\hline TOTAL & 100.0 & 100.0 & 100.0 & 100.0 & 100.0 & 100.0 \\
\hline \multicolumn{7}{|l|}{$\begin{array}{l}\text { Ratio of income share to } \\
\text { population share }\end{array}$} \\
\hline $15-19$ & 0.12 & 0.12 & 0.12 & 0.13 & 0.13 & 0.13 \\
\hline $20-24$ & 0.92 & 0.94 & 0.96 & 0.99 & 1.00 & 1.00 \\
\hline $25-34$ & 1.31 & 1.34 & 1.37 & 1.40 & 1.42 & 1.42 \\
\hline $35-44$ & 1.32 & 1.35 & 1.38 & 1.41 & 1.43 & 1.44 \\
\hline $45-54$ & 1.31 & 1.33 & 1.37 & 1.40 & 1.42 & 1.42 \\
\hline $55-64$ & 0.81 & 0.82 & 0.84 & 0.86 & 0.87 & 0.88 \\
\hline $65-74$ & 0.55 & 0.56 & 0.58 & 0.59 & 0.60 & 0.60 \\
\hline $75+$ & 0.58 & 0.59 & 0.60 & 0.62 & 0.62 & 0.63 \\
\hline TOTAL & $\ldots$ & $\ldots$ & $\ldots$ & $\ldots$ & $\ldots$ & $\ldots$ \\
\hline
\end{tabular}


An appreciation of this 'median individual effect' can be gained by examining the relative contribution to projected aggregate weekly income made by each age group. Table 2 gives each age group's projected percentage share of the working age population, their share of projected aggregate weekly income, and the ratio of these two indicators, which is the income contribution per person. The data show that 35-44 year olds in 2001 accounted for 19.1 per cent of the working age population, but contributed 25.3 per cent of aggregate weekly income, an income/population share ratio of 1.3. The underlying proportions at this age decline across the projection period, to 14.5 per cent, but their income to population ratio increases slightly, to 1.4 by 2051. In comparison, in 2001 and 2051 the age groups 15-19 and 20-24 years together account for 17.6 and 13.7 per cent respectively of the working age population, but only 9.2 and 8.0 per cent of aggregate income.

Sometime between 2041 and 2051, the median individual will move out of the high-earning 35-44 age group, and into the relatively high earning 45-54 age group. As a result, all else remaining equal, he or she and his or her proximate cohorts will continue to deliver a sizeable component of Australia's aggregate income well into the future. It is also likely that both the per capita and aggregate earnings of this age group will increase in time, as the baby boomers leave the labour market and their successors are encouraged to increase their labour force participation rates.

The passage of the median individual through the key income-earning age groups is one likely reason for the Guest and McDonald (2001 b, c) finding that population ageing will not greatly impinge upon Australia's future living standards. In short, this passage sustains the period of demographic gift, and, as Guest and McDonald argue, at least at national level, implies that government intervention is not in any way urgent in the short term.

\section{The Median Individual and Demographic Gift by State and Territory}

Again the analysis can be carried out at state/territory level. The results of this regional analysis appear in Table 3, which shows the year in which the median individual of each region entered or will enter the 35-44 year age group, the projected year in which he/she will leave and the resulting number of years of more narrowly concentrated demographic gift that each region can anticipate. Here we utilise two sets of ABS population projections to illustrate the likely parameters of change, the 'medium' variant (Series II) assuming lower net migration and fertility than previously noted for the 'high' variant (see ABS, 2000).

Two important findings emerge from this analysis. First, the median individuals of the Australian Capital Territory (ACT) and the Northern Territory are currently aged 33 and 30 years respectively, and have not yet even entered the all important 35-44 year age group, meaning that these regions have yet to look forward to the full benefits of their demographic gift. Indeed, the Northern Territory's median individual is not projected to enter this age group during the 
projection period - that is, before 2051 - under either projection series. Second, due to marked differences in the speed of population ageing and the impact of migration in each state and territory, there are equally marked differences in the number of years that each region will enjoy their gift. For example, under Series I (the high variant), both Tasmania and South Australia will enjoy 32 years of gift, while Victoria will reap the benefits for around 51 years. Under Series II (the medium case), Tasmania will enjoy only 24 years of gift, compared with 36 years for Victoria, 42 years for New South Wales and 47 for Queensland. The median individuals of New South Wales and Queensland (currently 36 and 35 years respectively) will not exit the 35-44 year age group during the entire projection period under the Series I assumptions, so it is not yet possible to ascertain their period of gift should these conditions prevail, while the median individuals of Western Australia, the ACT and the Northern Territory will not exit this age group during the entire projection period under either projection series.

Table 3: Actual and Projected Year in which Median Individual Will Enter and Leave 35-44 Year Age Group, by ABS Projection Series and State/Territory

\begin{tabular}{l|c|cc|cc|cc}
\hline & Median & \multicolumn{2}{|c|}{ Enter } & \multicolumn{2}{c|}{ Exit } & \multicolumn{2}{c}{ Period of 'gift' } \\
State & age 2002 & Series 1 & Series II & Series 1 & Series II & Series 1 & Series II \\
\hline SA & 37.9 & 1995 & 1995 & 2027 & 2025 & 32 & 30 \\
TAS & 37.7 & 1997 & 1997 & 2029 & 2021 & 32 & 24 \\
NSW & 36.1 & 1998 & 1998 & $2051+$ & 2040 & $\ldots$ & 42 \\
VIC & 36.0 & 1999 & 1999 & 2050 & 2035 & 51 & 36 \\
QLD & 35.3 & 2001 & 2001 & $2051+$ & 2048 & $\ldots$ & 47 \\
WA & 35.2 & 2002 & 2002 & $2051+$ & $2051+$ & $\ldots$ & $\ldots$ \\
ACT & 33.5 & 2010 & 2007 & $2051+$ & $2051+$ & $\ldots$ & $\ldots$ \\
NT & 29.9 & $2051+$ & $2051+$ & $2051+$ & $2051+$ & $\ldots$ & $\ldots$ \\
\hline TOTAL & 35.9 & 2000 & 2000 & $2051+$ & 2041 & $\ldots$ & 41 \\
\hline
\end{tabular}

Note: Shaded cells denote that entry and/or exit will not occur before 2051

Source: ABS (2000) Population Projections 1999-2100, Catalogue 3222.0

Finally, but to complicate matters slightly, the few exceptions to the rule that the 35-44 year age group is the highest earning age group need to be considered. These exceptions occur in the ACT and the Northern Territory, where the highest earning age group in each is currently that aged 45-54 years. The explanation for this disparity would seem to lie in the relatively large proportions of the economically active populations of these two regions employed in the relatively high-earning Government Administration and Defence industry, 23.9 per cent in the ACT and 17.7 per cent in the Northern Territory (ABS, 2003, Table 26b). By contrast, in 2001 the remaining six states had an average of 4.3 per cent of employed persons working in this key industry, ranging from 3.0 per cent in Victoria to 5.3 per cent in Tasmania. Relative proportions in each labour force 
status would of course also have a bearing on these statistics, as would the ratio of males to females at each age and in each industry and labour force status.

In the ACT and Northern Territory we also find that the 45-54 year age groups enjoy, respectively, the highest and second-highest per capita income of any age groups in any state/territory. Thus, not only have the median individuals of these two regions not yet entered their relatively high earning 35-44 year age groups, but they will not enter their very high earning 45-54 year age groups until sometime after 2051. Their demographic gifts will therefore be considerably greater than those of other states, and their respective periods of demographic gift will extend well beyond those implied in Table 3.

This does not mean that the projected aggregate earnings of the ACT and Northern Territory will necessarily follow the same trajectory. Instead, as indicated in Table 3, these are affected by the relative speed at which each region is ageing structurally (Jackson and Felmingham, 2002:102; see also Eding, 1999, and van der Gaag, 1999, using EU data), and thus by the relative size of their working age populations, vis-à-vis those of non-working age. Once the ACT passes the point at which it officially becomes an 'old' population (10 per cent over the age of 65 years - see Weeks, 1999:278-9), around 2007, it will undergo the most rapid ageing of any Australian State or Territory, taking just 25 years to transit the space between having 10 and 20 per cent aged 65+ years. This compares with 42 years for the country as a whole, ranging from 36 years in Tasmania and Western Australia to 44 years in New South Wales (Jackson and Felmingham, 2002:100-103). By contrast, the speed at which the Northern Territory will age is difficult to predict, since it is not projected to even reach the official 'old' population indicator of 10 per cent aged 65+ years until around 2047. The overall outcome for the ACT is that the data given in Table 2 would have shown much greater impact of population ageing were it not for the sustained presence of the median individual in the highest income-earning age groups.

\section{Summary and Discussion of Policy Issues}

This paper outlines Australia's experience of the demographic gift - the period during which the population age structure is optimal for the support of its younger and older members. The concept is applied to aggregate earnings for the period 1976-2001, and to projected aggregate earnings (2001-2051) to show first the economic impact of the gift as it has been enjoyed in Australia, and secondly an indication of its forthcoming loss, the legacy of population ageing. We show that over the 1976-2001 period, changes in age structure made a small but significant contribution to aggregate earnings, the percentage effect peaking around 1996. In 1996 this effect was worth approximately 7.8 billion dollars, and in 2001, although having fallen to 2.5 per cent of aggregate earnings, 8.2 billion dollars. Our projections to 2051 indicate that, ceteris paribus, population ageing will reduce aggregate earnings (over what they would be if it were possible for the age structure to remain constant) by around 1.9 per cent by 2011, increasing to 8.6 per cent by 2051. However, we argue that this impact will be ameliorated by the 
relatively slow movement of the median individual through the highest incomeearning age group, concentrating this aspect of the gift, and that the finding goes some distance to explaining those of other analysts, such as Guest and McDonald (2001b, 2001c), who argue that population ageing will have a minimal impact on other projected economic factors, such as aggregate savings.

The 'median individual' is the key player in this story. The significance of the median individual is that aggregate income will be at its maximum when he or she is in the highest income earning age group, and will decline as he/she moves through the age distribution to lower income earning groups. We show here that he or she and his/her proximate cohorts have in fact only just entered Australia's highest income-earning age group - that at 35-44 years - and will not exit this group until 2041 on the ABS medium case projections, and 2051 under the high variant. As a result, while the proportion of the total population that is at this age will decline over the 2001-2051 period, its contribution to aggregate income will increase. This effect will be sustained - albeit at a reducing rate - as the median individual moves into the next but typically lower-earning income-earning group, at age $45-54$ years.

However we also show that the situation differs markedly at the state and territory level, as these regions are undergoing markedly different rates of population ageing. Not only will the impact of population ageing on the aggregate incomes of each state/territory differ, but the median individuals of some states have not yet even entered the high-earning 35-44 year age group. The implications of these regional disparities are far-reaching, not least for the basis upon which fiscal transfers via the Commonwealth Grants Commission and States Grants Commissions are determined - highly complex issues that we have not been able to discuss in any detail here. But one very significant implication should at least be acknowledged; this is the argument that population growth influences economic growth only when it is associated with changes in the age distribution of the population; that it is the growth rate of the economically active population that is most positively correlated with economic growth, while population growth per se can actually have a negative effect (Bloom and Canning, 2003:6). As the compositional changes outlined above unfold across Australia's states and territories over a period of several decades, and usher in the related emergence of zero population growth and/or decline, it will be necessary to revisit many of the principles on which current grant allocation policies - which reward population growth - are based (see for example United Nations, 2000:4). We could argue, for example, that it is not the forthcoming regionally- and temporallydifferentiated shift to zero growth and/or decline of the working age population that is problematic, but rather, that current grant allocation polices are out of synchrony with this rapidly unfolding dynamic (Jackson forthcoming).

Indeed, overall, this study supports the general assessment made by Guest and McDonald in relation to living standards and population ageing, that no case for immediate large-scale policy intervention is needed. However, the quite disparate nature of the size of the demographic gift and its projected duration among the Australian states and territories is a different matter. Clearly, this 
disparity suggests that local as well as regional and national policy intervention is required. States Grants Commissions, for example, establish the basis of their 'disability factors' (population and other social, economic and geographical characteristics via which Local Governments are assisted to provide services) several years in advance. Institutional inertia means that these criteria cannot be changed readily, and raises the usual vexed question about policy coordination among the tiers of Australian government. In particular we note that the grant allocation process is a zero sum game played out between the states and territories. It is advantageous to move to a coordinated approach sooner rather than later, before these inter- and intra-regional tensions and issues emerge.

Also among these issues is likely to be the extent to which regionallydiffering rates of decline in the ratio of labour market entrants to exits may see a significant improvement in the employment and earnings circumstances of younger people, especially in the older regions. As population ageing unfolds there is likely to be an increase in competition within the labour market, and between the labour market and the tertiary education sector, for the participation of the same young people. Such demand could see the currently highest income earning age group pass downwards to a younger group, altering the distribution of income that our analysis has been based on, and, in particular, manifesting at different rates in the states and territories. It is critically important that such potential feedback mechanisms become a central consideration of social and economic policy making. Any increase in competition for the labour of the young would involve substantial adjustment costs in the labour market that would vary across the individual states and territories.

Mason (2003) argues that the manner in which the East Asian countries accomplished turning their demographic gift into economic advantage is important because of its potential value to other developing countries confronting similar changes. Central to the outcome was the attention given to absorbing the rapidly growing working age populations of these countries, over the 1960-1990 period. Policies included 'outward-looking strategies that encouraged domestic enterprises to compete in the global market place; stable macroeconomic policies that ensured low rates of inflation, discouraged capital flight and promoted economic efficiency; and the use of financial incentives, subsidies and access to credit to promote the growth of key [manufacturing] industries' (Mason, 2003:10). The main message of Mason's paper (and that of Bloom and Canning, 2003), is that failure to create an appropriate policy environment via which to capitalise on the demographic gift, risks a squandering of that gift. The message should not be lost on the policy makers of developed countries, many of which did squander at least part of their demographic gift, by permitting high levels of structural unemployment as the gift years peaked. As population ageing and the loss of the gift unfolds it is critical that both the challenges and opportunities presented by these demographic forces become more fully appreciated. 


\section{References}

Argy, F. (2001), 'Economic Rationalism in Australia - Survey of Members of the Economic Society of Australia ACT Branch’, Economic Papers 20(1):1-14.

Australian Bureau of Statistics (2000), Population Projections 1999-2100, Catalogue No. 3222.0.

Australian Bureau of Statistics (2003), Basic Community Profiles, Catalogue No. 2001.0.

Australian Bureau of Statistics (2003), Experimental Composite Leading Indicator Time Series Data, Catalogue No. 1350.0.65.001.

Australian Bureau of Statistics (various years), Births, Catalogue No. 3301.0.

Birdsall, N., A. Kelley and S. Sinding (2001), Population Matters: Demographic Change, Economic Growth, and Poverty in the Developing World, Oxford University Press, Oxford.

Bloom, D. and D. Canning (2003), 'From Demographic Lift to Economic Lift-off: the Case of Egypt', Applied Population and Policy 1:15-24.

Eding, H. (1999), 'Regional Population Ageing of the EU at Different Speeds up to 2015', Statistics in Focus, Theme 1, No. 4, Eurostat, Netherlands Interdisciplinary Demographic Institute.

Fitzgerald, V. (1993), National Saving: A Report to the Treasurer, AGPS, Canberra.

Guest, R. and I. McDonald (1998), 'The Socially Optimal Level of Saving in Australia 1960-61 to 1994-5’, Australian Economic Papers 37(3):211-229.

Guest, R. and I. McDonald (2001a), 'National Saving and Population Ageing', Agenda 8(3):235-246.

Guest, R. and I. McDonald (2001b), 'Would a Decrease in Fertility be a Threat to Living Standards in Australia?’, Australian Economic Review 35(1):29-34.

Guest, R. and I. McDonald (2001c), ‘Ageing, Optimal National Saving and Future Living Standards in Australia’, Economic Record 77(257) June:117-134.

Jackson, N. (forthcoming), 'Regional Population Ageing and Local Government Funding. A Tentative Consideration of the Issues', Australasian Journal of Regional Studies.

Jackson, N. and B. Felmingham (2002), 'As the Population Clock Winds Down: Indicative effects on Australia's States and Territories', Journal of Population Research, 19(2):97-117.

Kippen, R. and P. McDonald. (2000), 'Australia's Population in 2000: The Way We Were, and the Ways We Might Have Been’, People and Place 8(3):10-17.

Mason, A. (2003), 'Population Change and Economic Development: What Have We Learned from the East Asia Experience?’, Applied Population and Policy 1:3-14. 
Pollard, A., F. Yusuf. and G. Pollard (1974), Demographic Techniques, Pergamon Press, Rushcutters Bay, NSW.

United Nations (2000), Replacement Migration, Population Division, Department of Economic and Social Affairs, United Nations Secretariat.

Van der Gaag, N. (1999), 'Recent Population Decline in the EU: Recent Trends and Future Perspectives', Statistics in Focus, Theme 1, No. 3, Eurostat, Netherlands Interdisciplinary Demographic Institute.

Weeks, J. (1999), Population: An Introduction to Concepts and Issues, Seventh Edition, Wadsworth, Belmont CA.

Wood, A. (2001), 'Raising Levy isn't a Super Idea in Election Year', The Australian, April 10.

This research was funded by an ARC-Linkage grant. The authors would like to thank the anonymous referees and the editor for their insightful comments on this paper. We also thank our research assistants. We remain responsible for any errors or omissions. 